\title{
LA INFLUENCIA DE LOS MEDIOS MASIVOS EN LA FORMACION DEL SUJETO: UNA PERSPECTIVA PSICOANALÍTICA
}

RESUMEN. Al ser desde hace tiempo los medios masivos de difusión la institución que puede considerarse como hegemónica en los procesos de socialización e ideologización de nuestra época, este artículo resume una investigación en desarrollo sobre el aporte de los mismos - desde una perspectiva teórica psicoanalítica - al proceso de formación del sujeto psicosocial.

Palavras-chave: medios masivos, formacion del sujeto, psicoanálisis.

\section{THE INFLUENCE OF THE MASSIVE MEDIA IN THE INDIVIDUAL'S FORMATION: A PSYCHOANALYTICAL PERSPECTIVE}

\begin{abstract}
To the human being, for some time, the massive means of communication are the institutions that can be considered hegemonic in the socialization processes and ideologization of our time. The present article summarizes an investigation in development on the contribution of the means of communication - from a psychoanalytical theoretical perspective - the process of formation of the psychosocial individual.
\end{abstract}

Key words: means of communications, individual's formation, psychoanalisis ${ }^{1}$

El rol de los medios masivos de difusión en la formación del Sujeto siempre ha sido muy señalado pero poco estudiado por las ciencias sociales y los comunicólogos en general y el campo psi en particular. Por supuesto que ya es casi un lugar común señalar su importancia en todos los terrenos de la vida y del mundo desde hace muchas décadas, pero las investigaciones teóricas sobre cómo lo hacen respecto a la formación psicosocial brillan por su ausencia o se limitan a ver el problema desde perspectivas cerradamente disciplinarias, donde por parte de las llamadas "ciencias sociales" no se tienen en cuenta los esenciales aportes que pueden brindar los marcos teóricos de la psicología (y el psicoanálisis en particular) cuya especificidad es precisamente el estudio del sujeto. Carencia, como se indicó, tanto de los investigadores de la comunicación como de los propios psicoanalistas que poco (e incluso prácticamente nada) estudian la influencia de los medios en la psico(pato)logía del sujeto de nuestro tiempo, pese a reconocer su existencia e importancia ${ }^{1}$.

¿Se continuará en esta cerrazón disciplinaria o, más allá de las buenas intenciones al respecto, se abrirá el conocimiento a una perspectiva

Psicólogo, Maestría en Ciencias de la Comunicación, Doctorado en Estudios Latinoamericanos. Profesor-Investigador Titular en la Universidad Autónoma Metropolitana-Xochimilco, México DF. Director de la revista Subjetividad y Cultura.

Endereço para correspondência: E-mail: gbje1567@cueyatl.uam.mx

1 Por supuesto siempre hubo intentos de acercamiento o de alguna vinculación entre diferentes perspectivas disciplinarias, pero nunca o del todo logradas o seguidas por otros autores. Sin duda una de las más fructíferas fue la de la Escuela de Frankfurt, que incluía al psicoanálisis entre sus marcos teóricos, así como desarrolló interesantes análisis sobre el rol de los medios masivos, en particular su noción de industria cultural que sigue siendo tan necesaria como útil para nuestros tiempos (Horkheimer \& Adorno, 1974). Sin embargo ninguno de sus principales exponentes (Adorno, Horkheimer) llegaron a estudiar de manera intensa un vínculo como se desarrolla en este trabajo, aunque ofrecieron aportes muy valiosos. 
transdiciplinaria? ¿Se comprenderá que es imposible el estudio del sujeto sin incorporar los conocimientos de quienes analizan su proceso de estructuración y de cambio? ¿Por su parte el mundo psi aceptará que este proceso hoy no se limita a la familia y a las instituciones socializadores tradicionales (escolares, religiosas, etc), sino también con intervención de unos medios que para muchos hoy son hegemónicos, por lo que inciden cada vez más y penetran de manera cuantitativa y cualitativa en los sujetos desde su propio nacimiento? (Guinsberg, 1995 y 1999) 2 .

Por eso es importante el estudio de algo de particular trascendencia. Tal el propósito de este trabajo que, por razones de espacio, se limitará a una síntesis de diversas investigaciones ya realizadas causa de la gran cantidad de autocitas bibliográficasbuscando comprender cómo y por qué se produce tal incidencia de los medios masivos de difusión ${ }^{3}$ en el proceso de constitución del Sujeto así como proponiendo una forma de estudio que permita una integración de los procesos de emisión y de recepción, hoy muchas veces vistos por separado (Guinsberg, 1989/2002, 1990b, 1991a).

\section{LOS MEDIOS COMO SUJETADORES}

Si para este estudio se parte de un marco teórico psicoanalítico, ésto no debe preocupar por muchas de las posturas de nula o escasa comprensión del sujeto como ser social que se encuentran en tal escuela. Por el contrario, aquí se considera a ésta como el paradigma teórico que mejor comprende a la subjetividad pero ubicándola dentro de los procesos culturales, a diferencia del psicoanálisis ortodoxo, tradicional y domesticado hoy predominante (Guinsberg, 1991b/1996a, 2000a). Con esto se quiere decir que se entiende al psiquismo como

2 Múltiples datos demuestran que si bien la familia sigue teniendo un peso afectivo central, es bastante menor respecto a los procesos de ideologización y construcción de la realidad, donde la relación medios-grupos juveniles tienen un peso hoy fundamental. Escribiendo este artículo leo un interesante ejemplo personal al respecto (tal vez sin conciencia de su significación) que presenta la conocida crítica "globalifóbica" Naomí Klein, donde destaca que la ideología cuestionadora de su familia no tuvo importancia en su adolescencia, donde estaba subyugada por la de su contorno y la de los medios (Klein, 2001, p. 180).

3 Si bien generalmente se utiliza medios masivos de comunicación se prefiere definirlos como de difusión porque en su actual uso no se fomenta lo primero, que técnicamente sería posible, sino lo último desde una perspectiva vertical. indefectiblemente conformado y atravesado por los procesos sociales e históricos concretos que actúan en el proceso de socialización. Al respecto El malestar en la cultura puede ser vista como una obra de Freud donde categóricamente se manifiesta tal postura, obra no casualmente postergada o "negada" por quienes se resisten a la crítica de las formas sociales, eliminando de tal manera el carácter cuestionador e incluso "subversivo" del psicoanálisis ${ }^{4}$.

Desde tal perspectiva se trata de analizar el aporte de los medios a la construcción del sujeto junto a otras instituciones (la familia en particular aunque ya no de manera tan preponderante). Y una forma de encarar la tarea es a partir del modelo de aparato psíquico que propone tal escuela, aunque obviamente Freud nunca encaró tal aporte de los medios ante la escasa importancia de los mismos en su época (la prensa no tenía la gran difusión actual, la radio estaba en sus inicios, y la televisión no existía).

Un primer y fundamental aspecto a señalar es que, como ya se indicó, los niños conviven actualmente con los medios desde el inicio de su vida, al punto que para ellos el televisor "es un aparato receptor que ya forma parte de la ecología familiar" (Arredondo, 1989, p. 9), y de manera muy acelerada desde hace un tiempo se incorporan al mundo electrónico en sus diversas formas (juegos, internet, etc.), lo que refuerza el peso tanto de su poder como el de unos contenidos que penetran a niveles inconcientes, situación que continuará a lo largo de toda la vida en un momento donde los medios, sobre todo los electrónicos, incrementan su capacidad de llegada y de internalización en la subjetividad. En este sentido es importante destacar que la importancia de tal penetración no pasa sustancialmente por los criticados mensajes subliminales en el sentido perceptivo de estos, sino por las significaciones de la infinita cantidad de mensajes que los sujetos reciben cotidianamente a través de la múltiple gama de programas (informativos, de diversión, etc), donde muchas veces los contenidos manifiestos son la cubertura de los latentes (en emisión y recepción).

\footnotetext{
4 "Subversivo" en el sentido de ser la "peste" que Freud señaló en 1909 por haber provocado una ruptura con los conocimientos anteriores e incluso haber chocado con la moral de la época por sus aportaciones acerca de las nociones de inconciente, sexualidad y sexualidad infantil. En cuanto a Freud, si bien en algunas ocasiones formuló importantes críticas al marco social de su época destacando la necesidad de cambios, nunca sistematizó una crítica ni aplicó los conocimientos psicoanalíticos a su realidad política, lo que comenzó a hacerse posteriormente con base en algunas lecturas de su obra.
} 
Respecto a la estructuración del aparato psíquico, recordemos que el niño nace puro Ello (instancia pulsional básica regida por el "principio del placer"), a partir de los cuales se forman el Yo y el Superyo en el citado proceso de socialización que se realiza con la intervención de las múltiples instituciones sociales citadas.

La constitución del $Y o$ es producto tanto de un complejo proceso de identificaciones como del paulatino reemplazo del principio del placer por el principio de realidad. Y si bien, como ya se dijo, clásicamente se consideró que en ambos es la familia la que tiene el rol central - con el apoyo de las instituciones escolares y religiosas-, hoy no puede negarse ni minusvalorizarse la creciente influencia de los medios masivos de difusión, con mayor razón por llegar antes que tales instituciones o cuando no se accede al aparato educativo (aspecto de fuerte peso en muchas naciones o zonas subdesarrolladas con bajos niveles de alfabetización).

Es cierto que los modelos identificatorios ${ }^{5}$ básicos surgen sobre todo de los vínculos afectivos del niño con sus relaciones directas (padres, abuelos, maestros más tarde, etc), Pero ¿cómo dejar de ver que hoy el niño se encuentra en contacto con múltiples modelos y figuras provenientes de un televisor con el que se relaciona desde siempre, luego con caricaturas, juego electrónicos, etc? Modelos de todo tipo (actores, deportistas, vedettes, galanes, protagonistas de series y telenovelas) no sólo llamativos, impactantes y deseados por su éxito, omnipotencia, belleza, etc, sino que también cambian en formas y nombres pero mantienen significados - por ejemplo Batman, Superman, El Hombre Nuclear, la Mujer Maravilla, etc. como exponentes de un poder y fuerza que los niños ven en el padre pero ante los cuales éste puede quedar comparativamente devaluado (aunque sea real y los otros sean parte de un mundo de fantasía aunque aún no bien delimitada respecto a la realidad)-, y dejan una evidente secuela, aunque hasta ahora no analizada cuantitativa y cualitativamente con el rigor que merece. Una simple e incluso elemental observación sobre los comportamientos de nuestro tiempo permite ver cómo existe un muy alto grado de identificación con múltiples figuras televisivas, cinematográficas y musicales: imitación de gestos, conductas y vestimentas, adopción de sus nombres en juegos

5 "Proceso psicológico mediante el cual un sujeto asimila un aspecto, una propiedad, un atributo de otro y se transforma, total o parcialmente, sobre el modelo de éste. La personalidad se constituye y se diferencia mediante una serie de identificaciones" (Laplanche, J. \& Pontalis, J-B., 1971, p. 190). deportivos con la consiguiente asimilación de ellos, etc.

Asimismo, junto a esa llegada directa a partir de la recepción de programas infantiles o para adultos, existe otra indirecta a través del entorno familiar y educativo -ya formados e ideologizados por los medios -, compañeros de juegos, etc. que transmiten comportamientos, normas, modelos, "necesidades" y actitudes cotidianas fomentadas por los héroes prototípicos, anuncios publicitarios, consejos de personajes admirados y seguidos, etc. En este sentido no puede olvidarse que el juego es una expresión típica del mundo infantil que no responde sólo a una actividad de diversión sino también es expresión de sus necesidades afectivas - por eso las terapias se hacen mediante su ejercicio-, lo que hace que jugar con imágenes de los héroes televisivos o juguetes promocionados por las emisoras, o a ser tales héroes implica la internalización de las significaciones y contenidos de los mismos: se trata de un modelo a imitar y a seguir. Al respecto es evidente que los modelos promocionados de manera positiva son aquellos que responden a los valores de una cultura determinada, mientras que se hace lo contrario con aquellas expresiones rechazadas por ella.

En cuanto al paso del principio del placer al de realidad resulta evidente la incidencia de los medios al ser éstos actualmente no sólo los que muestran a esta última sino incluso "construyen" lo que debe entenderse por "realidad". Evidencia que recalcan numerosos estudiosos, por ejemplo Eliseo Verón al afirmar categóricamente que "los medios informativos son el lugar donde las sociedades industriales producen nuestra realidad" (Verón, 1983, p. II), o Christian Doelker que considera que "la construcción de nuestra imagen del mundo se realiza cada vez más a través de los medios, que a su vez proporcionan una imagen del mundo: por consiguiente, nuestro concepto de realidad nace -según nuestra proporción de consumo de los medios- asimismo de experiencias mediatas y no tan sólo de experiencias inmediatas" (Doelker, 1982, p. 177). Como las "experiencias inmediatas" son muy pocas en relación a las que cada persona conoce ${ }^{6}$, puede decirse sin duda alguna que en la absoluta mayoría de los sujetos actuales la idea que tiene acerca de la "realidad" es producida por los medios en general y la TV en particular (actualmente la principal fuente noticiosa en prácticamente todo el mundo, sobre todo en los países subdesarrollados

\footnotetext{
Incluso muchas veces éstas buscan ser corroboradas por lo que los medios dicen sobre ellas (caso de accidentes, acciones deportivas, etc.).
} 
donde los niveles de lectura son bajos). Se trata, como se ha analizado y escrito reiteradamente, de una óptica determinada de la "realidad" -la más de las veces no plural y sólo representativa de los intereses de los detentadores del control de los medios y/o del poder-, y que en múltiples y mayoritarias situaciones puede ser diferente, parcial e incluso globalmente, a la realidad (esta vez sin comillas).

No es ninguna novedad que los acontecimientos (políticos, sociales, económicos, deportivos, etc.) muchas veces "no existen", o pierden importancia y trascendencia, si no se informa de ellos en los medios o si lo hace sin darles la importancia que tienen. Así como que algo sin mayor valor lo adquiere cuando se hace fuerte énfasis en ello, no faltando casos donde algunos hechos se "construyen" para los medios. En este sentido es importante recordar cómo los estudios sobre comunicación destacan la construcción por éstos de lo que Shaw llamó la agenda-setting, teoría que sostiene que "como consecuencia de la acción de los periódicos, de la televisión y de los demás medios de información, el público es consciente o ignora, presta atención o descuida, enfatiza o pasa por alto, elementos específicos de los escenarios públicos. La gente tiende a incluir o a excluir de sus propios conocimientos lo que los media incluyen o excluyen de su propio contenido. El público además tiende a asignar a lo que incluye una importancia que refleja el énfasis atribuido por los mass media a los acontecimientos, a los problemas, a las personas" (Wolf, 1987, p. 163) ${ }^{7}$.

Como destaca este autor, "los media, al describir y precisar la realidad externa, presentan al público una lista de todo aquello en torno a lo que tener una opinión y discutir [...] El presupuesto fundamental de la agendasetting es que la comprensión que tiene la gente de gran parte de la realidad social es modificada por los media". En otras palabras, los medios indican en lo que debe pensarse y en lo que no, y en múltiples casos, también qué debe pensarse o al menos tienden a influir en esta perspectiva.

Es sabido que el principio de realidad es un aspecto central en la estructuración de los sujetos, y que el pensamiento y la conducta de los hombres estará basada en su idea de realidad: de allí la necesidad de dar

7 El señalamiento de esta importancia no debe confundirse con una absoluta omnipotencia. Si siempre hubo personas y sectores sociales que han resistido a una influencia que actúa sobre vastas mayorías, hoy esto se reitera ante la conocida oposición mundial (incluso dentro del mismo país atacante) a la guerra de invasión iniciada por Estados Unidos sobre Irak pese a la acción de la mayoría de los medios masivos (aunque debe tenerse en cuenta que, salvo la TV estadounidense, múltiples medios del mundo no han caído en una postura de apoyo a tal guerra). un sentido a la misma o enmascarar el conocimiento de lo que no se quiere que se conozca. Un yo desconocedor del real sentido de la realidad actuará de manera poco eficiente para modificar lo que se pretende que no se modifique, o buscará cambiar aquello que se le muestra que no debe permanecer como está.

Es esto lo que explica la fundamental importancia que los poderes establecidos otorgan a la posesión y control de los medios (sobre todo, por su llegada, a los electrónicos), convertidos en instrumentos centrales del "control social".

Esta situación incuestionablemente real (aquí sin comillas) produce una extraña aunque conocida paradoja: en momentos de un tremendo auge de comunicación e información en prácticamente todo el mundo, los niveles de incomunicación y desinformación son muy grandes y generalizados. Es inmensa la cantidad de diarios, revistas, canales de radio y TV existentes -lo mismo que aparatos receptores- pero lo que se difunde y transmite parece más ocultar o distorsionar que mostrar: el caso de la llamada Guerra del Golfo es un caso tal vez extremo pero también paradigmático ${ }^{9}$. Se cree dominar el conocimiento de la realidad, pero muchas veces se trata de una fantasía (y no pocas veces de un delirio). En este sentido la aparente saturación informativa -aparente porque no siempre la pluralidad es verdadera: la mayoría de los medios informan $y$ ocultan (tal vez con variantes) acerca de lo mismo ${ }^{10}$-, produce el muy conocido efecto

El control social siempre ha sido y es imprescindible para todo tipo de dominación, y tiene una fundamental importancia en la actualidad donde es más sutil que en otras épocas. Sobre esto véase dos artículos publicados últimamente en la revista Subjetividad y Cultura (Guinsberg, Matrajt, Campuzano, 2001; Ventre, 2002).

9 Sobre esto véase Ignacio Ramonet $\mathrm{y}$, sobre todo, Dominique Wolton (1992). Desde el 11 esto se reitera a niveles mayúsculos para justificar la llamada "guerra contra el terrorismo" y el ataque a Afganistan y hoy a Irak (análisis específicos sobre el tema en Guinsberg 2002 y 2003).

10 Es realmente muy importante recalcar que uno de los mitos de la actualidad es la real multiplicidad de opciones en los medios masivos. Si bien es cierto que existen múltiples revistas, periódicos y estaciones de radio y televisión, también lo es que la absoluta mayoría no son sino variaciones de contenidos similares, máxime en posturas ideológicas y políticas que se acrecientan en situaciones límites como, por ejemplo, lo fueron la citada guerra del Golfo y los atentados del 11de septiembre de 2001, donde perspectivas distintas tienen escasa o nula difusión. Lo que Ignacio Ramonet propuso exitosamente como "pensamiento único" (Ramonet, 1998) aumenta constantemente ante el control cada vez mayor de las grandes empresas editoriales y de medios por parte de grandes conglomerados trasnacionales. 
boomerang de "saturar" a los receptores e incluso de insensibilizarlos.

La realidad que se menciona de manera alguna debe limitarse a los noticieros, sino está presente en todas las programaciones, habiendo llegado a decirse que puede haber tanta realidad en (por ejemplo) una telenovela como ficción en un informativo. Las más de las veces el éxito de tales telenovelas precisamente se apoya en que el contenido no real tiene una base real que lo hace factible y no pura ilusión. Lo importante a destacar es que tal presentación de la "realidad" transmite una visión de la misma - de manera latente y muchas veces explícitamente manifiesta - cargada de determinadas significaciones y valores, casi siempre (o prácticamente siempre) los de la/s ideología/s imperante/s. Esto implica entonces no sólo los mensajes antes citados al yo, sino también modelos identificatorios, caminos de éxito y de logro de satisfacciones, mostración de premios y castigos (con destino al superyo), modelos de "salud mental" y de conductas normales y aprobadas, etc., todo ello presentado como expresión de la "realidad" a la que es preciso ajustarse en contraposición a lo "raro", lo "loco", lo peligroso, lo "malo", etc. Es evidente que todo es, por causas obvias, facilmente perceptible en las programaciones dirigidas a los niños.

Mostración de una "realidad" que, como ya se dijo, también señala los caminos reales, "adecuados" y "correctos" para la obtención del éxito y el logro de las satisfacciones, sea de manera concreta (más allá de la validez o posible discusión acerca de estos caminos) o a través de la catarsis y/o la evasión.

En la medida en que todo sujeto actúa de acuerdo a lo que entiende por "realidad", es comprensible que se busque que todos o la mayoría de una sociedad compartan la que interesa que se vea como tal a los sectores del poder, sea para mantener la estructura existente o dificultar las transformaciones que atenten contra ella. Por eso todo lo ampliamente estudiado y conocido acerca de los silencios y censuras sobre aspectos considerados peligrosos, tergiversaciones $\mathrm{y}$ distorsiones, fragmentación de la "realidad" para evitar el conocimiento de la totalidad, etc. Esta es una de las formas más claras para lograr que el sujeto se encuentre sujetado al sistema en que vive.

En cuanto al Superyo, "una de las instancias de la personalidad (cuya) función es comparable a la de un juez o censor con respecto al yo, y que Freud considera la conciencia moral, la autoobservación, la formación de ideales como sus funciones" (Laplanche \& Pontalis, 1971, p. 440), es incuestionable como recibe constantes y permanentes señalamientos de unos medios donde los "malos" que hacen cosas "malas", de acuerdo a la moral y la ética dominante, siempre fracasan y son castigados, mientras los "buenos" triunfan y reciben premios de diferente tipo. Una persona triunfadora y aceptada será aquella que cumple con lo que la moral vigente indica, consume aquello que se indica que tiene que consumir y tiene "lo que hay que tener". Los personajes de los medios que deben ser imitados son modelos por sus perfecciones como, en no pocos casos, pecaron y se salieron del redil pero supieron reconocer la culpa y se arrepintieron por sí mismos o guiados por los eficientes guardianes de las normas estatuídas. "En nuestra sociedad -señala un estudioso norteamericano que comprende el fenómeno pero no del todo su sentido- se nos enseña que hay ciertas cosas que podemos hacer y otras que no podemos hacer; de este modo se nos introduce a los valores y a las normas. El proceso de socialización, que es continuo y se ubica en las personas y las instituciones, y puede no sólo ser deliberado sino además inadvertido, consiste en parte en la internalización de múltiples 'haz esto' y 'no hagas aquello', de 'bien' y de 'mal', de 'verdadero' y 'falso', propios de la sociedad de que se trate. Ni el contenido ni los métodos de socialización son inmunes a la influencia de los medios de comunicación de masas; la manipulación y el cambio pueden tener lugar y de hecho lo tienen. Los medios de masa, se puede admitir, constituyen sólo un aspecto del proceso, pero sería muy sorprendente, en verdad, si no desempeñaran un cierto papel en la modelación de nuestras actitudes respecto de la vida, de nosotros mismos y de los demás" (Halloran, 1969, p. 29) ${ }^{11}$.

En prácticamente todas las programaciones masivas constantemente aparecen valores, las más de las veces de manera explícita, pero no presentados como de un sector una época sino con características universales y tal vez permanentes, un claro ejemplo de lo cual es el siguiente: "Televisa [la principal cadena de TV eb México] - dijo su jefe de Control y Normasno maneja ninguna tendencia. Expresa la superación personal, la integración familiar y la superación nacional que yo creo que son valores eternos. Mire, quiero que quede muy claro el concepto. No es que la manejemos [la ideología] porque de ninguna manera pretendemos manejarla. Si de alguna forma, algún ejemplo que pudiéramos pasar a través de la televisión, no concreto sino genérico, ayuda a la gente

11 Por supuesto que aquí se presenta una idea muy general sobre esto como sobre todo lo planteado en este artículo. Por supuesto que no siempre es así -aunque sí es lo marcadamente dominante- y existen programaciones (incluso en caricaturas para niños) con visiones diferentes y críticas o contradictorias con las de la mayoría, no pocas de ellas exitosas (caso de los Simpson) o que escapan a las intenciones concientes de sus autores y productores. 
a tratar de superarse, creo que es válido en cualquier ideología, en cualquier sociedad y en cualquier época de la vida" (Ricalde, 1979, p. 8).

Es evidente como esto último se vincula de manera directa con criterios de salud mental y de normalidad, otras de las formas centrales de sujetación de un sujeto al hacerse ver la necesidad de evitar la "locura" y/o la "anormalidad" y los peligros que ocasionan. Un muy rápido comentario al respecto es que no existen criterios claros ni fijos respecto a "salud mental" - se trata de una concepción polivalente que varía notoriamente de acuerdo a diferentes marcos teóricos y procesos históricos-, y que "normalidad" sólo hace referencia a un fenómeno estadístico que indica lo que es mayoritario pero que de manera alguna es equivalente a "salud mental" (puede incluso ser lo contrario).

¿Hay acaso dudas de que los medios masivos -de manera muchas veces explícita pero siempre implícitamente- fomentan la "normalidad" que implica una adaptación acrítica, o mínimamente crítica pero no antagónica, a los usos y costumbres de su sociedad, definiendo como "no sano", "enfermo" o "loco" lo que se le oponga? (Guinsberg, 1990a-1996). Aunque, como se verá después, aceptan y promueven cambios pero en tanto estos sean necesarios para la continuidad y renovación de la forma cultural vigente.

En todo lo anterior puede verse como los medios cumplen actualmente un papel importante en la conformación del sujeto, y todo indica que tal rol no sólo continuará sino que se incrementará ante el gran desarrollo de los medios electrónico que, entre tantas otras innovaciones, está produciendo un fuerte "culto a la información" (que en realidad lo es a la "informática"). De aquí proviene una de las principales causas -por supuesto nada nueva- de la búsqueda del control de los medios, por la conciencia que se tiene de que ella implica en gran medida el control de los hombres, medio cada vez más necesario para el mantenimiento del poder en un momento histórico de triunfo de postulaciones entendidas como "democráticas", donde son reprobados los usos de posturas totalitarias y represivas manifiestas ${ }^{12}$.

12 El problema del control de las conciencias ha sido muy estudiado desde siempre. Entre tantos trabajos al respecto (no todos seriamente encarados) véase, por los datos que proporciona el de Y. Eudes (1984), y por la crudeza en defender la manipulación publicitaria y el control de las mentes, el de Ernest Dichter (1964). Por supuesto el tema sigue siendo de primordial importancia en épocas donde las técnicas al respecto son mucho más sofisticadas: en relación al campo publicitario ver mi libro (1987).
Tal papel de los medios ya lo veía hace décadas un lúcido y crítico sociólogo, que formula una excelente síntesis al respecto: "Los medios masivos de comunicación: 1) le dicen al hombre de masa quién es: le prestan una identidad; 2) le dicen qué quiere ser: le dan aspiraciones; 3) le dicen como lograrlo: le dan una técnica; 4) le dicen cómo puede sentir que es así, incluso cuando no lo es: le dan un escape" (Wright Mills, 1957).

\section{SUJETO Y “NECESIDADES” PSÍQUICAS}

Lo anterior es un muy apretado resumen de la acción de los mensajes sobre el psiquismo de los receptores. Pero ¿por qué estos los aceptan, incluso cuando responden a intereses diferentes e incluso contrarios a los propios (desde el punto de vista del mantenimiento de factores económicos, de poder, etc)? o, como dicen los Mattelart, “¿por qué las clases populares 'invierten deseo y extraen placer' de esa cultura que los niega como sujetos?" (Mattelart, 1987, p. 120$)^{13}$.

Es cierto que en muchas oportunidades no existen opciones de elección, pero lo señalado también existe cuando las hay, por lo que es necesario buscar otras respuestas. Y un planteo de Freud abre fundamentales caminos para el estudio: "(el psicoanálisis) parte de la representación básica de que la principal función del mecanismo anímico es aligerar a la criatura de las tensiones que le producen sus necesidades. Un tramo de esta tarea es solucionable por vía de la satisfacción, que uno le arranca al mundo exterior; para este fin se requiere del gobierno sobre el mundo real. A otra parte de estas necesidades -entre ellas, esencialmente, ciertas aspiraciones afectivas-, la realidad por regla general les deniega la satisfacción. Toda la historia de la cultura no hace sino mostrar los caminos que los seres humanos han emprendido para esta ligazón de sus deseos insatisfechos, bajo las condiciones cambiantes, y alteradas por el progreso técnico, de permisión y denegación por la realidad" (Freud, 1976a, p. 118, subrayados míos).

Con base en que el hombre se encuentra con una contradicción insoluble y que jamás podrá superar enteramente (aunque sí mejorar) -surge como humano a partir de las relaciones sociales, pero éstas requieren de normas colectivas que no permiten acceder a la satisfacción de todos los deseos de los individuos, los

13 Aunque habría que señalar que tal fenómeno de manera alguna es exclusiva de las clases populares. Un desarrollo mayor de lo que sigue en el cap.10 de Control de los medios (...) 
que son permitidos, negados o reglamentados de formas distintas por cada cultura y a través de la historia-, éstos buscarán una real o aparente satisfacción para sufrir las carencias al mínimo posible.

Por supuesto que esto último tiene una especial importancia para las pulsiones, tanto sexuales como las agresivas, ya que "lo decisivo será que se logre (y la medida en que se lo logre) aliviar la carga que el sacrificio de lo pulsional impone a los hombres, reconciliarlos con la que siga siendo necesaria y resarcirlos por ella" (Freud, 1976d, p.7, subrayado mío). Si bien el creador del psicoanálisis considera que "misión de los dioses será ahora compensar las deficiencias y los perjuicios de la cultura" (Freud, 1976d, p. 12) -es decir será una de las tareas de las religiones-, en la misma obra más adelante señala que "después de haber discernido las doctrinas religiosas como ilusiones, se nos plantea otra pregunta: ino serán de parecida naturaleza otros patrimonios culturales que tenemos en alta estima y por los cuales regimos nuestras vidas? (p.34, subrayado mío). Y si bien no menciona a los medios por lo antes indicado, el objetivo que hace surgir tal necesidad es uno que éstos también cubren y que ayuda a explicar el éxito que tienen: "Éstas que se proclaman enseñanzas [se refiere a las religiosas pero se pueden extender a otras formas] no son decantaciones de la experiencia ni resultados finales del pensar: son ilusiones, cumplimiento de los deseos más antiguos, más intensos, más urgentes de la humanidad; el secreto de su fuerza es la fuerza de estos deseos" (p. 30, subrayado mío).

Es por eso que Freud también dirá muchos años después en el ya citado trabajo central sobre la relación hombre-cultura -en una afirmación que algunos ven como producto de su supuesto pesimismo, pero que se muestra muy real-, que "la vida, como nos es impuesta, resulta gravosa: nos trae hartos dolores, desengaños, tareas insolubles. Para soportarla no podemos prescindir de calmantes. Los hay, quizá, de tres clases: poderosas distracciones, que nos hagan valuar un poco nuestra miseria; satisfacciones sustitutivas, que la reduzcan, y sustancias embriagadoras que nos vuelvan insensibles a ellas. Algo de este tipo es indispensable"(Freud, 1976b, p. 75, subrayados míos).

Más allá de lo complejo del análisis freudiano al respecto -muy difícil de estudiar e incluso de captar en sus significaciones en pocas líneas-, ¿acaso pueden existir dudas de que los medios son quienes actualmente proporcionan de manera central a nivel masivo tales "calmantes", posibilitando la "satisfacción” de necesidades afectivas no siempre (o totalmente) realizables en la realidad? ${ }^{14}$.

Distracciones, satisfacciones sustitutivas, también materiales embriagantes (en el sentido genérico de quienes hablan de "adicción" a los medios) son pan cotidiano de unos medios que permiten el acceso al mundo de la fantasía de todo tipo y para todos los gustos, que posibilitan la identificación con deseos irrealizados (aunque sea a través de otros y de la ficción), que también permiten la catarsis de expresiones reprimidas (eróticas y agresivas en primer lugar), que crean imágenes prototípicas y "caudillescas" de nuevo tipo ${ }^{15}$ que brindan acceso a también identificaciones de nuevo cuño y diferentes a las tradicionales. Y por supuesto en esta lista pueden agregarse otras situaciones igualmente importantes.

$\mathrm{Si}$ bien los medios funcionan como los "calmantes" para prácticamente todos los aspectos de la vida actual, es interesante ver un poco más detalladamente su papel sobre las limitaciones que toda cultura impone a las dos pulsiones ya mencionadas. Uno, lógicamente, se vincula "a aquella orientación de la vida que sitúa al amor en el punto central, que espera toda satisfacción del hecho de amar y ser amado". Y una visión de esto aparentemente tan sencillo muestra sus dificultades, realidad no sólo limitada a una mirada psicoanalítica: siempre, y tal vez más la realidad contemporánea, indica importantes carencias al respecto, y mucho más si tal realidad se mide en comparación con las expectativas siempre absolutas del principio del placer que se tienen (hoy también fomentadas por los medios). "El programa que nos impone el principio del placer -dirá Freud-, el de ser felices, es irrealizable; empero, no es lícito -más bien: no es posible- resignar los empeños por acercarse de algún modo a su cumplimiento. Para esto pueden emprenderse muy diversos caminos [...] Por ninguno de ellos podemos alcanzar todo lo que anhelamos" (Freud, 1976b, p. 83). Si esto se dice respecto al amor, algo respetado casi de manera unánime, es que resulta mucho más difícil para la sexualidad que, aunque ha tenido importantes avances de permisividad en todos los sentidos en las últimas décadas, sigue siendo objeto de prejuicios, limitaciones y temores.

14 Al decirse que "de manera central" significa que por supuesto hay muchas otras.

15 El importante y clásico estudio de Freud al respecto, Psicología de las masas y análisis del yo (1976c), por este motivo hoy requiere de modificaciones ante la no desaparición pero sí disminución de los "caudillos" conocidos anteriormente y la aparición de los creados o fomentados por los medios. 
¿Acaso no es evidente que los prodigiosos éxitos de los mensajes relacionados con el amor, los vínculos afectivos, la sexualidad, etc., y los múltiples conflictos que surgen de ellos, se apoyan en las necesidades de los receptores, es decir en sus propios conflictos y carencias? En tanto que los requirimientos del principio del placer nunca alcanzan su realización de manera completa -y la mayor parte de las veces se encuentran muy lejos de ésta- siempre se mantiene la búsqueda a través de formas sustitutivas que hoy los medios ofrecen en variantes de todo tipo y para todas las necesidades. Por eso tienen éxito hasta las fantasías más increíbles y delirantes desde el punto de vista argumental, pero que permiten el desarrollo de la fantasía, identificaciones y catarsis de receptores que, aunque sea en la ficción, "satisfacen" algunos de sus deseos.

En cuanto a las tendencias agresivas ${ }^{16}$ Freud señala la conocida dificultad de su ejercicio y la represión a la que es sometida, pero más allá de las causas de esta última, vale para ellas la misma necesidad de al menos una cierta descarga, que no siempre es posible por sublimaciones y catarsis. No es por tanto nada extraño ver en esta carencia el inmenso éxito de la casi infinita cantidad de programaciones de todo tipo con temáticas o escenas violentas que siempre han existido y que alarman no sólo a las mentalidades "bienpensantes" sino a importantes sectores de la sociedad. También aquí existen variantes para todos los gustos, pero es interesante observar que estos contenidos violentos están muy presentes en programaciones infantiles donde prácticamente siempre existen peleas, combates, competencia, etc. ${ }^{17}$.

Puede verse que la incorporación de este acercamiento al estudio de los medios no sólo aporta niveles fundamentales de conocimiento - hasta ahora prácticamente no abordados por los estudiosos de la comunicación, que hace poco empezaron a

16 Recuérdese que Freud las teoriza como pulsión recién en 1920 en Más allá del principio del placer, algo que no es aceptado por todas las escuelas analíticas.

17 Sobre la relación TV y violencia véase un trabajo anterior (2000b) mucho más extenso y detallado, donde se presentan tanto estadísticas acerca de su presencia, multitud de estudios al respecto, como se formula la hipótesis de que su actual mantenimiento y acrecentamiento se vincula al modelo neoliberal que busca mostrar a niños desde la más temprana infancia que la violencia es intrínseca a unas formas sociales social-darwinistas cada vez más competitivas, así como que el éxito y el triunfo sólo son posible a través de ella e incluso violando las normas legales (casos de la corrupción, el narcotráfico, etc.) descubrir ${ }^{18}$-, sino también abren campos nuevos de abordaje a viejos problemas. Entre ellos y sólo a modo de ejemplos:

- Una relación distinta del estudio de los procesos de emisión y de recepción, hasta ahora muchas veces vistos como separados ${ }^{19}$ o viendo al último sin la incorporación de los saberes acerca de la subjetividad y del sujeto (lo que hoy resulta ya imperdonable $)^{20}$. Respecto a lo primero debe recordarse que el estudio de los procesos de recepción no es nuevo pero se ha vigorizado mucho en los últimos tiempos al punto de casi convertirse en una "moda" con base en la ruptura con la idea conductista acerca de un receptor pasivo, que acaba con las conocidas como "teoría de la bala" o de la "aguja hipodérmica" donde el sujeto no ofrece resistencias a los mensajes que recibe. Por el contrario, ahora se ve al receptor como activo en un contexto donde su aceptación o rechazo de los mensajes es producto de múltiples causas y "mediaciones": y es aquí donde nuevamente, como puede verse en todo lo anterior, el campo psi en general y el psicoanalítico en particular puede aportar mucho para la comprensión de tal proceso tanto a niveles individuales como grupales, sociales colectivos, etc. Incluso sobre esto es importante la

18 Otra vez son los Mattelart los que lo reconocen: "Las nociones de placer y de deseo son puntos centrales en las estrategias de quienes hoy todavía piensan en términos de conquista de audiencia y de industrialización de los contenidos, y que mañana pensarán más en términos de placer individualizado (...) Al descubrir el placer ordinario, es, por último, la verdadera naturaleza del entorno cultural de la mass mediación la que la teoría crítica puede comenzar a explorar. Esta ocultación del placer encierra algo aberrante. ¿Cómo ha podido ignorarse tan masivamente este aspecto esencial de la realidad?" (Mattelart, 1987, p. 128).

19 Por supuesto debe vérselos como una dialéctica, donde el actual control de los medios ofrece y fomenta determinados productos, aunque con base en un claro conocimiento de gustos y necesidades de los receptores, pero para canalizar ésto a sus intereses.

20 Con "imperdonable" se quiere decir que no se puede aceptar la afirmación de un valioso estudioso de los procesos de recepción respecto a la. "imposibilidad de acceso a las mentalidades infantiles", acceso que realiza cualquier profesional psi o incluso un comunicólogo más o menos conocedor de este campo. Aquí es válido el señalamiento de los Mattelart respecto a que "es cierto que aun si nadie niega el papel de lo afectivo, la dificultad está en llegar a conocer sus procesos (...) Aquí se plantea el problema de los vínculos con el psicoanálisis“ (Mattelart, 1988, p. 82). 
recuperación, aunque desde diferente marco teórico, de la conocida teoría de "usos y gratificaciones" de los medios masivos, que formula consideraciones similares a las anteriores pero desde una perspectiva conductista.

- El campo de la comunicación y la política, donde las agencias publicitarias han ido -de manera pragmática y a veces también teórica- mucho más lejos que los políticos y los comunicólogos ${ }^{21}$ y aunque también con base en cambios que se han producido en el campo político- la mercadotecnia ha reemplazado los usos y prácticas anteriores para vender programas y candidatos como si fueran mercancías de acuerdo a estudios donde importan más slogans, vestimentas, etc. que las propuestas que se formulan ${ }^{22}$.

\section{LOS MEDIOS DE LOS MEDIOS}

Como ya se indicó, los medios no son los causantes de las situaciones que se viven pero sí sus principales promotores por el peso que tienen desde hace ya mucho tiempo como mostradores $y$ divulgadores de los sistemas en donde funcionan. Lo que ha sido siempre su tarea, no importando los modelos sociales, políticos y económicos a los que sirvan. Aunque ahora, como es muy conocido, su incidencia ha cambiado en importante grado muchas de las prácticas sociales (política, deportiva, etc) y el papel de sujeto en y ante ellas..

No es el caso de reiterar todo lo anteriormente dicho sobre por qué y cómo lo hace, pero sí insistir que su gran influencia no lo es tanto por sus mensajes explícitos sino por su mostración de un determinado tipo de realidad, premios y castigos para los sujetos, etc. Aunque el estudio concreto de sus mecanismos y técnicas actuales sea necesario tanto para conocimiento de las formas presentes del control social y tal vez como defensa, aunque sea parcial, frente a ellas.

Una investigación ya encarada y que debe ser continuada y profundizada desde una perspectiva tanto inter como transdisciplinaria, en particular sobre cada realidad concreta, que para nuestra época es la neoliberal hegemónica (Guinsberg, 2001).

21 Sobre la utilización de métodos publicitarios en el estudio de la comunicación (aunque con diferentes objetivos) véase mi artículo (1994).

22 Un desarrollo mucho mayor de esto en la parte final de mi Tesis de Doctorado en Estudios Latinoamericanos, de próxima edición (2003a) en Plaza y Valdés, México.

\section{REFERENCIAS}

Arredondo, P., (1989). Presentación. En Sánchez Ruiz, E. (Comp.), Teleadicción infantil: ¿mito o realidad? (pp. 7-8), Guadalajara: Universidad de Guadalajara.

Dichter, E. (1964). La estrategia del deseo.Buenos Aires: Huemul.

Doelker, C. (1982). La realidad manipulada. Barcelona: G.Gili.

Eudes, Y. (1984). La colonización de las conciencias.México: G.Gili.

Freud, S. (1976a). El interés por el psicoanálisis. En Obras completas (Tomo XIII, pp.169-192). Buenos Aires: Amorrortu.

Freud, S. (1976b). El malestar en la cultura. En Obras completas (Tomo XXI, pp. 65-140). Buenos Aires: Amorrortu.

Freud, S.(1976c).Psicología de las masas y análisis del yo. En Obras completas (Tomo XVIII, pp. 67-136). Buenos Aires: Amorrortu.

Freud, S. (1976d). El porvenir de una ilusión. En Obras completas (Tomo XXI, pp. 5-56). Buenos Aires: Amorrortu.

Guinsberg, E. (1987). Publicidad: manipulación para la reproducción. México: Plaza y Valdés/Universidad Autónoma Metropolitana-Xochimilco.

Guinsberg, E. (1990a y 1996). Normalidad, conflicto psíquico, control social. ( $1^{\mathrm{a}}$ y $2^{\mathrm{a}}$ ed.) México: Plaza y Valdés/UAM Xochimilco.

Guinsberg, E. (1991b-1996a).La relación hombre-cultura: eje del psicoanálisis. Subjetividad y Cultura México (1), p. 7-22. [reproducido en la $2^{\mathrm{a}}$ ed. del libro Normalidad, conflicto psíquico, control social (pp. 419-440), México: Plaza y Valdés.]

Guinsberg, E. (1999). Televisión y familia en la formación del sujeto. En Lozano, J. y Benassini, C. (Ed), Anuario de Investigación de la Comunicación V (pp. 31-53), México: Consejo Nacional para la Enseñanza y la Investigación de las Ciencias de la Comunicación / Universidad Iberoamericana.

Guinsberg, E. (2000b) Televisión y violencia. En Kurnitzky, H. (Comp.), Globalización de la violencia (pp. 183202).México: Colibrí.

Guinsberg, E. Matrajt, M. y Campuzano M. (2001). Subjetividad y control social: un tema de hoy y siempre. Subjetividad y Cultura (16), p. 7-26

Guinsberg, E. (2002).El control social en 'tiempos de guerra'. En Anuario de Investigación 2001 (pp. 61-74), México: Departamento Educación y Comunicación, Universidad Autónoma Metropolitana-Xochimilco.

Guinsberg, E. (2003a). El malestar en la cultura en América Latina, México: Plaza y Valdés, (libro de próxima edición).

Halloran, J.D. (1969). Examen de los efectos de las comunicaciones de masas con especial referencia a la televisión. En Bell, D., Adorno , T. W., Shils, E., Horkeheimer, M., Merton R., Lazarsfeld, P. e Donald, M. D., Los efectos de las comunicaciones de masas (pp. 7-43). Buenos Aires: Jorge Alvarez Editor.

Klein, N. (2001). No logo: el poder de las marcas. Barcelona: Paidós. 
Laplanche, J. \& Pontalis, J-B. (1971). Diccionario de psicoanálisis. Barcelona: Labor (la actual edición es de Paidós).

Mattelart, A. y M. (1987).Pensar sobre los medios. Madrid: Los libros de Fundesco.

Mattelart, A. y M. (1988).El carnaval de las imágenes. Madrid: Akal/Comunicación.

Ramonet, I. (1998).El pensamiento único. En Le Monde Diplomatique edición española, Pensamiento crítico vs. Pensamiento único (pp. 15-17). Madrid: Temas de Debate.

Ricalde, E. (1979). Entrevista en revista Alternativa, México: UAM-Xochimilco.

Wolf, M. (1987). La investigación de la comunicación de masas. Crítica y perspectivas. Barcelona: Paidós.
Wolton (1992). War game: la información y la guerra. México: Siglo XXI.

Ventre, M. (2002).La globalización y las nuevas formas de control social. Subjetividad y Cultura, (16), p. 7-26.

Verón, E. (1983). Construir el acontecimiento. Buenos Aires: Gedisa.

Wright Mills, C. (1957). La elite del poder. (1 $1^{\text {a }}$ ed.) México: Fondo de Cultura Económica

Recebido em 30/09/2002

Revisado em 11/04/2003

Aceito em 30/05/2003 